\title{
Methodological approaches to the assessment of capitalization of construction enterprises
}

\author{
Inessa Lukmanova ${ }^{1, *}$, Andrey Chizhik ${ }^{2}$, Alexander Fadeev $^{3}$, Yaroslav Lavrinenko ${ }^{4}$ and \\ Elena Sharapova ${ }^{4}$ \\ ${ }^{1}$ Moscow State University of Civil Engineering, Yaroslavskoye sh., 26, 129337 Moscow, Russia \\ ${ }^{2}$ Moscow Aviation Institute, Volokolamskoe highway, 4, Moscow, 125993, Russia \\ ${ }^{3}$ Bauman Moscow State Technical University, 2nd Baumanskaya street, 5/ 1,105005, Moscow Russia \\ ${ }^{4}$ Voronezh State Technical University, Moscow Avenue, 14, 394026, Voronezh, Russia
}

\begin{abstract}
The paper is devoted to the study of methodological approaches to the assessment of capitalization of construction enterprises. The main objective of the study is the development of a strategy map of the enterprise, focused on the growth of its capitalization. The analysis of typology of capitalization mechanisms of companies is presented; author's recommendations on the arrangement of the financial mechanism of the company's fundamental capitalization are given. Theoretical approaches are considered and the influence of external and internal factors on the process of increasing the value of enterprises of the construction industry is determined. The mechanisms of capitalization are revealed and systematized due to the analysis of expansion of construction enterprises. The developed strategy map allows us to graphically identify the key factors that influence the creation of a high level of capitalization.
\end{abstract}

\section{Introduction}

Insufficient development of capitalization issues, as well as the low level of development of capitalization processes against the backdrop of a tendency of reducing the level of innovation activity of enterprises, intensifies the theoretical and practical significance of research aimed at studying the capitalization processes of the construction enterprise as a part of a group of interrelated participants.

Successful implementation of this task involves the development of an algorithm for the capitalization mechanism based on the implementation of the new forms of activity. These factors determined the relevance of the research and also had a direct influence on the setting of targets and objectives [1].

\section{Materials and methods}

Today, modern researchers distinguish two types of theories of the orientation of the enterprise within the conditions of its capitalization: traditional and alternative.

\footnotetext{
*Corresponding author: lukmanova@mgsu.ru
} 
Figure 1 presents the classification of the theories mentioned above.

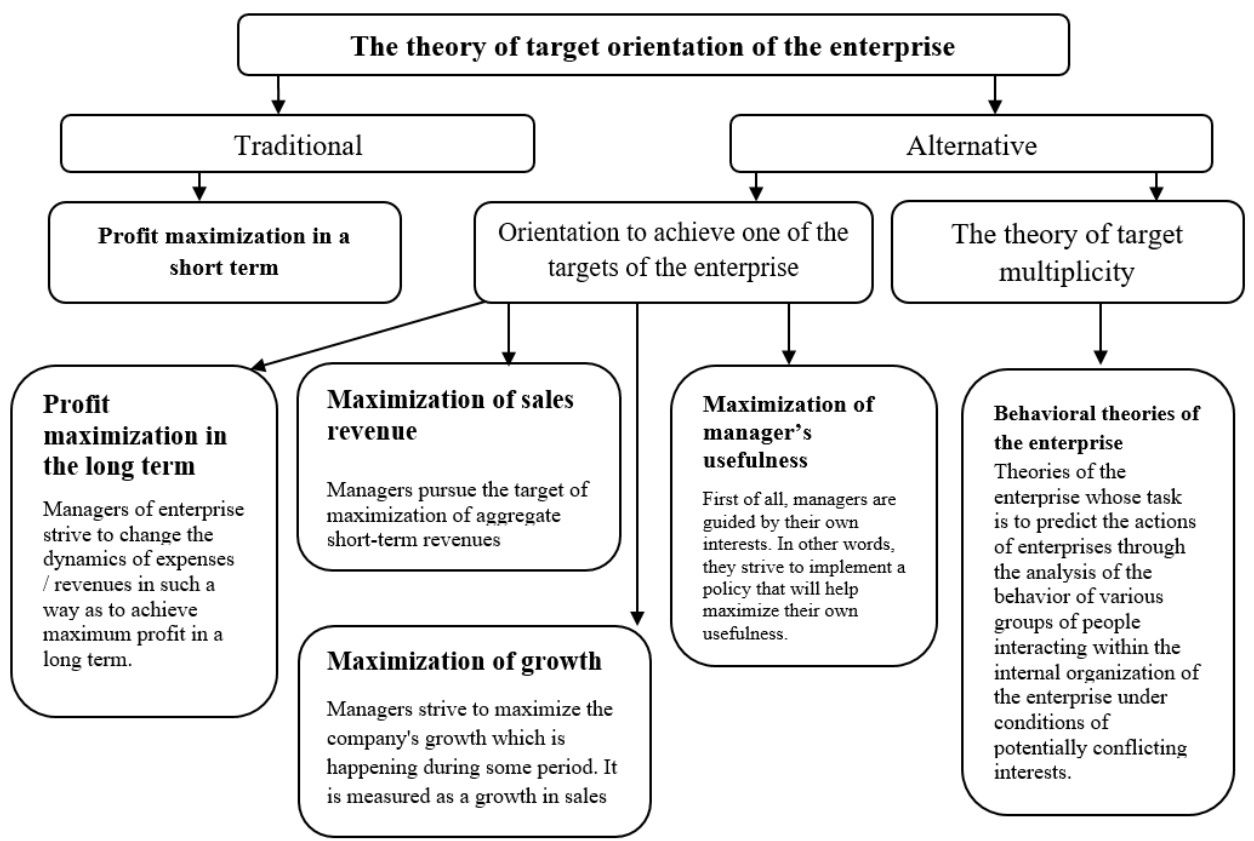

Fig. 1. The classification of the theories of target orientation of the enterprise within the conditions of its capitalization.

1. Traditional theory of the enterprise. Within the framework of this theory, the main target of the enterprise is to maximize profits in a short term. There is a rule of profit maximization: profit reaches its maximum level when the marginal revenue is equal to the marginal cost. Comprehensive analysis of revenues and costs allows determining at what level of production the profit of the enterprise will be maximal and also the value of this profit. By analyzing the curves of average and marginal cost, as well as the curves of marginal and average revenue, it is possible to compare the possibilities of profit maximization in a short term under different market conditions. Within a short-term period, one (or more) factor of production has a permanent character.

Traditional theory is often criticized by researchers for inability to properly assess the real behavior of an enterprise. There are two main areas of criticism:

- traditional theory does not always explain why enterprises that strive to maximize profits are not able to solve this problem for one reason or another;

- inability of the traditional theory to analyze the behavior of enterprises that pursue other targets besides maximization of profits during their activities.

An important role in profit maximization is played by the time period. The enterprise should determine the period in which it is necessary to maximize profits. It is necessary due to the fact that it functions in the constantly changing environment. If the enterprise chooses a particular price index or production volume that will be optimal for profit maximization in the current period, then it may endanger the dynamics of profitability in the future.

2. Alternative theories of the enterprise. Modern researchers, criticizing the traditional theory, come to the strategy of obtaining the minimum satisfactory level of profit. Managers, as the realizers of the capitalization process, are usually not interested in the maximization of profit of the enterprise. Their target is to maximize their own usefulness and own equity. However, managers strive to ensure that the profit of the enterprise is not below the certain sufficient level [2]. 
There are two main categories of alternative theories:

- based on the assumption that in the conditions of achieving the minimum required level of profit, enterprises strive to maximize a different target (such theories include: maximization of profits in a long term, maximization of sales revenues and maximization of growth);

- according to which enterprises pursue the objectives of achieving several conflicting targets, only one of which is aimed to achieve the minimum required level of profit (behavioral theories).

The traditional theory of the enterprise is based on the thesis that the enterprise pursues the target of maximization of profits in a short term. Because of this, scientists put forward an alternative theory of the enterprise to consider the process of maximization in a long term.

On the basis of the alternative theory, the enterprise's policy aimed to increase the range of activity or market share may imply advertising campaigns or price reduction campaigns. This will in a long term lead to an increase of the enterprise and gaining the larger market share, so the resulting economic power will allow increasing the profits. But it should be noted that the alternative theory does not allow providing the accurate forecasts of the enterprise's behavior and can be empirically verified with a great difficulty [3].

The theory of maximization of usefulness for managers is considered as one of the most powerful alternative theories of the enterprise [O.E. Williamson]. He claimed that in the situation when the enterprise has reached a minimum satisfactory level of profit, managers of the enterprise often receive the freedom of action to determine the future policy of the enterprise. In other words, they are free to realize their own interests.

There are several factors that determine the usefulness of the manager:

- wage;

- guarantee of employment;

- domination (social status, power, prestige);

- professional excellence.

Only one of these factors, namely the wage, is measurable. The level of significance of the rest can be determined indirectly: through an analysis of the expenses made by managers, including personnel expenses, benefits, and discretionary investments. The higher the level of expenses under these headings, the more significant are the status, the range of managerial authority, prestige, guarantee of employment, professional excellence, and therefore the usefulness of the manager.

The growth of the activity of enterprise should be measured by increasing the volume of revenue from sales (or turnover). The alternative method of measuring the range of the enterprise is to measure the value of the fixed capital of the enterprise, but the fact should be taken into account that this indicator depends on the dynamics of the securities market, and therefore may not be reliable enough.

For the successful implementation of the strategy of maximization of the growth of the range of activity, it is important to correctly establish the price and the volume of production of the enterprise. On the one hand, in a short term the enterprise can choose the tactics of determination of the optimal price and production level in order to obtain funds for investing more long-term projects. On the other hand, it can invest the part of a shortterm profit in expanding the scale of advertising activities. These measures are determined by the strategy which is regarded by management as the most appropriate for solving the problems of maximization of growth. The long-term forecast of the price and volume of production is quite a difficult task because it is necessary to analyze market opportunities to determine the development strategy. The disadvantage of this analysis is that it is easy to manipulate: each researcher can interpret the calculated result in his own way, and, 
consequently, the prospects for the development of the enterprise will be assessed in the different ways [4].

According to the practice, those enterprises that strive to maximize the growth of the range of activity choose the strategy of differentiation of their products, if the resources of the enterprise for expanding the already existing market are close to depletion.

The theory considered above assumed that the enterprise has only one target (profit, volume of sales, growth) which is maximized. However, there is another category of alternative theories - behavioral theories that have multiple targets.

Over the last years, enterprises are increasingly striving to implement several targets at once, for example, to increase the sales revenue, as well as to increase their profit. However, the difficulty lies in the fact that if two targets are in conflict with each other, their maximization is impossible. Let's say that the level of prices and production volumes, which is optimal from the point of maximization of sales revenue, can be different from the level of prices and production volumes, which is optimal from the point of maximization of profit. Therefore, the enterprise must find a solution that would allow identifying the tasks that are consistent with its strategic targets.

Summing up all of the above, the following conclusion can be drawn: the multiplicity of the development theories converges to one target pursued by the enterprise - the increase of the level of capitalization of its activities. On the basis of the choice of the way of capitalization, the enterprise must be guided by the external environment and internal opportunities. It should be noted that there is a rational analysis in each theory, which helps to understand the actions of modern enterprises, to predict their future and to assess the consequences.

Most of construction enterprises are trying to increase their level of capitalization under current conditions of development of market economy.

Foreign researchers [R. Kaplan, D. Norton] connect the factors of increasing the cost (capitalization) with the development of a strategy map which illustrate all stages of the increment of the capital of the enterprise. The strategy map allows making the process of increasing the cost (capitalization) balanced; as a result, there is a steady and constant growth of capitalization.

The strategy map is a diagram used to document the main strategic targets set for the enterprise or the management of the enterprise [5].

Strategic targets are closely related and directly affect each other. The success of any strategy depends on the interaction of many factors which affect the level of capitalization of the enterprise. The main purpose of the strategy map is to identify the most optimal way to implement the general strategy of the construction enterprise. Many existing models of strategy maps are similar to the one described by Kaplan and Norton in their writings. It contains the main perspectives: finance, customers, business processes, training and development [6].

An example of the strategy map is shown in Figure 2. 


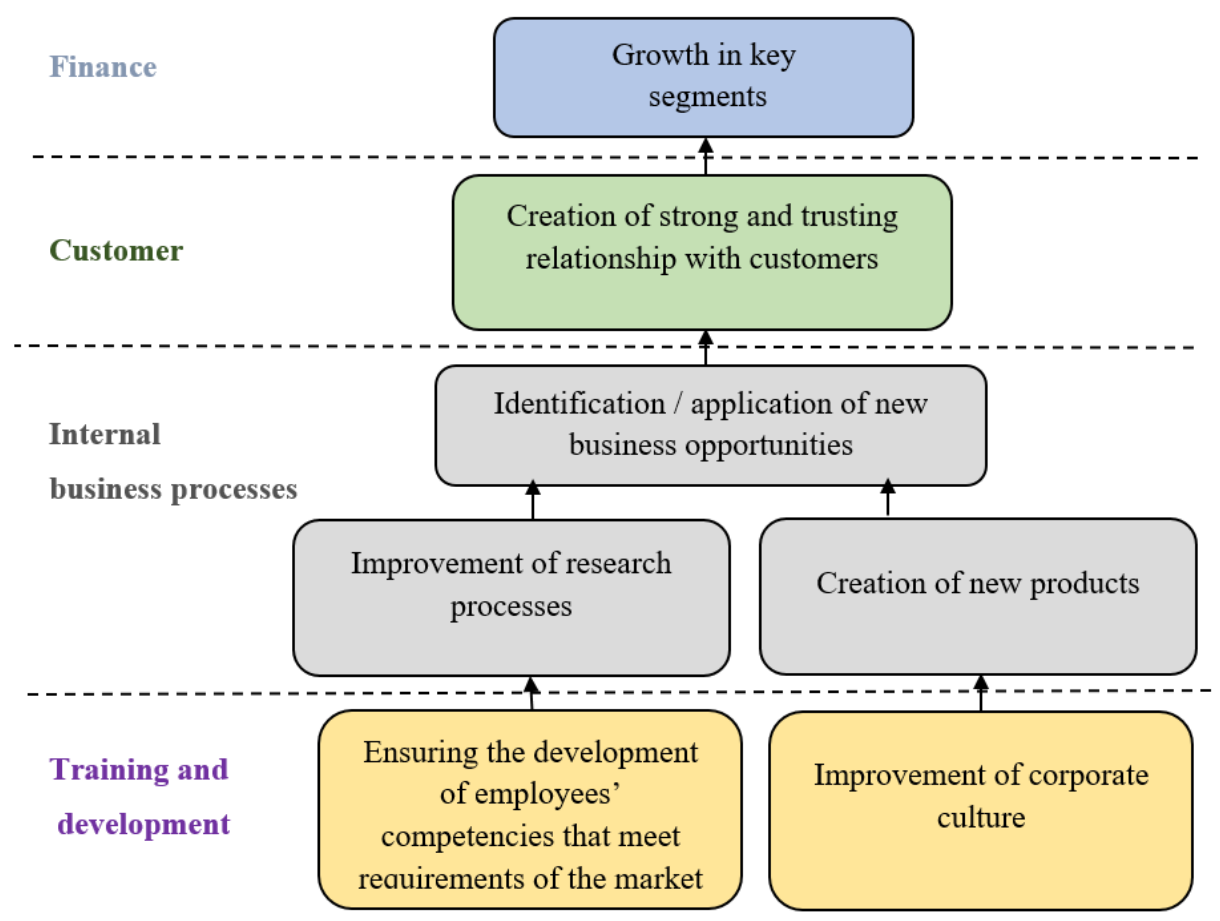

Fig. 2. Fragment of the enterprise strategy map.

In the study, the authors put forward a model of a strategy map called "EP ${ }^{2} \mathrm{M}$ " (Effective Progress and Performance Measurement) [7]. According to this model, the most important is the assessment of efficiency of the enterprise in four aspects:

- in the external environment - customer service and meeting the demand;

- in the internal environment - increasing of efficiency and productivity;

- top-down approach in the organizational structure - distribution and adaptation of the enterprise strategy to the all lower levels of the organizational structure;

- bottom-up approach in the organizational hierarchy - the increasing of the influence of shareholders and the expanding of the freedom of action of employees.

The concept of this model is that the assessment system should be directed not only to the implementation of the strategy, but also to the development of a corporate culture that recognizes the constant progress.

\section{Results}

Based on the above, the strategy map, in the process of implementation of a system of balanced indicators and its integration with the concept of value-oriented management, can be presented in the form of a model (Fig. 3). The strategic target of this model is to increase the level of capitalization of the enterprise. Such a strategy map allows graphical identification of key factors that affect the creation of a high level of capitalization [8]. 


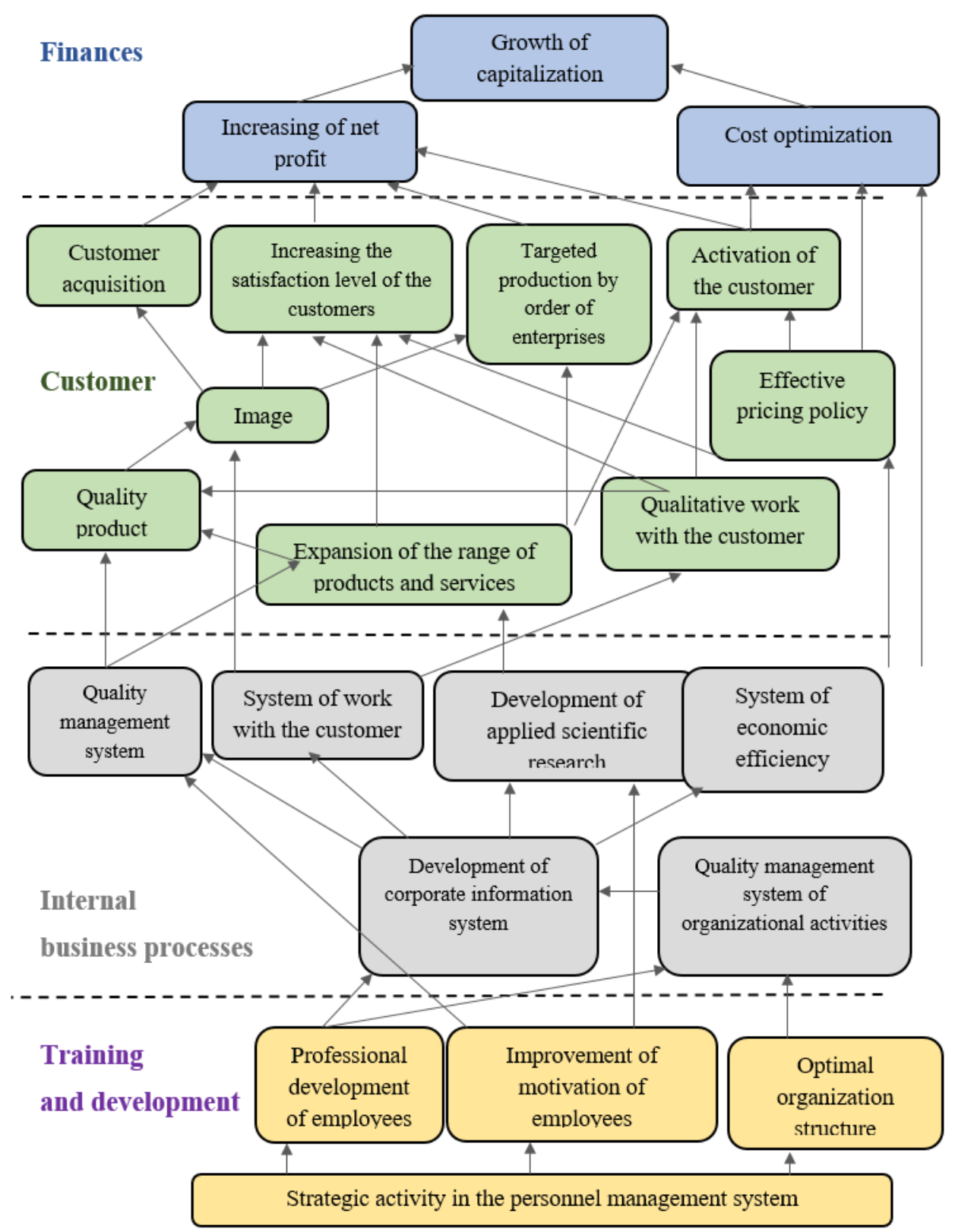

Fig. 3. The strategy map of the enterprise oriented on the growth of capitalization.

\section{Conclusion}

Based on the above, the conclusion that the process of capitalization is affected by both internal and external factors could be done. In other words, the level of capitalization is directly related to the situation in the country, as well as to the mechanisms within the enterprise. In order to increase the level of capitalization, it is necessary to have a stable and favorable situation in the country, which would allow construction enterprises to increase their tangible and intangible potential. It is also important for enterprises to create an 
effective integrated management system where the interaction of factors will lead to a rapid growth of capitalization.

\section{References}

1. I.G. Lukmanova, A.G. Korolyov, E.V. Nezhnikova, Project Management (MGSU, 2013)

2. K. Adams, P. Roberts, «EP2M» Effective Progress and Performance Measurement (1993)

3. A. Jones, G. Fallon, R. Golov, European Business Review 12(4), 187-197, doi: 10.1108/09555340010336871

4. I.V. Ilin, A.I. Levina, O.Yu. Iliashenko, MATEC Web of Conf. 86, 05028 (2016) doi:10.1051/matecconf/20168605028

5. V. Murgul, MATEC Web of Conferences, 02012 (2016)

6. F. Aggogeri, A. Avanzini, A. Borboni, S. Pandini, International Journal of Automation Technology 11(2), 311-321 (2017)

7. P. Kostrikin, E. Buadze, Review of the Southwest State University 1(64), 83-92 (2016)

8. A. Mottaeva, IOP Conf. Series: Earth and Environmental Science 90, 012120 doi:10.1088/1755-1315/90/1/0121209 (2017) 